\title{
From Context to Curriculum: A Case Study of Communicative Language Teaching in China
}

\section{Guangyong Sun and Liying Cheng}

This article discusses the implementation of communicative language teaching methodology in the EFL context in one institution in China. The context and curriculum development of the English teaching program at Private Pui Ching Commercial College is used here as a case study. The article suggests that a preliminary stage of context-based communicative curriculum development is necessary. Such a preliminary stage aims to investigate first the context of an English language teaching program, and then the process of adapting the program to its context for implementation. A framework for such a context investigation is proposed. Three key questions regarding the integration of the context study into curriculum design are also discussed.

Dans cet article, on discute de la mise en place de la "Communicative Language Teaching Methodology" (méthode communicative pour l'enseignement des langues) dans un contexte d'ALP au sein d'une institution en Chine. Le contexte et le développement du curriculum du programme d'enseignement de l'anglais dans un collège commercial privé (Private Pui Ching Commercial College) servent de cas d'étude. Les auteurs suggèrent qu'il est nécessaire de développer, dans une étape préliminaire, une pédagogie communicative basée sur le contexte. Cette étape permettrait d'abord l'étude du contexte d'un programme pour l'enseignement de l'anglais, et ensuite l'adaptation du programme à son contexte dans le dessein d'une mise en cuvre. Les auteurs proposent un cadre pour une telle étude de contexte et discutent de trois questions clés touchant son intégration dans la conception du curriculum.

\section{Introduction}

Communicative language teaching (CLT) has been regarded as the major innovation in language teaching methodology since the 1970s (Habermas, 1970; Hymes, 1971; Jakobovits, 1970; Savignon, 1972) and is now possibly the most prevalent approach in teaching English as a second language (TESL). In spite of the success of CLT in TESL, its efficacy in teaching English as a foreign language (TEFL) is still a controversial topic (Anderson, 1993; Cooke, 1986; Harvey, 1985; Li, 1997; Maley, 1984; Penner, 1995; Sampson, 1984). It could be argued that the issue of context in foreign-language teaching did 
not gain its significance until CLT was introduced to EFL teaching. For other methodologies such as audiolingual, grammar-translation, and situational methodology, teaching and learning activities take place in the domains of textbooks and an explicit syllabus. The content of these classes is predetermined and systematically programmed. Different contexts do not make distinctive differences to such programs. Teaching and learning using these methodologies are, therefore, relatively independent of context. On the contrary, CLT methodology, as it emphasizes authentic language input, real-life language practice, and creative generation of language output, is highly dependent on the situational context. CLT requires both a language setting to provide authentic input of language use and opportunity for the students to use the language in a realistic way. The use of CLT also implies the use of wide-ranging materials and the employment of highly qualified teachers to manage the creative classroom potentials (Bachman, 1990; Breen \& Candlin, 1980; Brown, 1994b; Brumfit, 1984; Howatt, 1984; Nunan, 1988; Richards \& Rogers, 1986; Savignon, 1997).

Developing in immersion settings, CLT does not always repeat its success in EFL countries. EFL teachers have complained that CLT was designed for second-language, rather than foreign-language teaching ( $\mathrm{Li}, 1997)$. For example, because CLT is now prevalent in ESL classrooms in English-speaking countries, some expatriate teachers of English from those countries tried to introduce CLT into their Chinese EFL classrooms, but the success rate was much lower than in the ESL programs in their home countries. The methodology, therefore, sometimes failed to attract local instructors and students (Barlow \& Lowe, 1985; Burnaby \& Sun, 1989; Penner, 1995). In most cases the traditional ways of teaching English resumed when those expatriate teachers left China.

The dependence of CLT on situational context seems to be a way to understand this failure. When communicative language teaching methodologies were transferred from an ESL to an EFL context, the differences between TESL and TEFL seem to have been overlooked. Moreover, the complexity of the EFL context has been inadequately estimated.

In our opinion, the nature and diversity of EFL contexts have not been fully explored. Stern (1983) outlined some of the differences in the two contexts (e.g. language environments and learners' motivations), but the implications of these differences were not discussed in detail. Sampson (1984) raised some fundamental questions that revealed the cultural, politi$\mathrm{cal}$, and educational gaps between different countries. McKay (1992) demonstrated a wider awareness of this issue and discussed it from the perspectives of expatriate teachers. As there exists huge diversity in values, traditions, cultures, political regimes, and educational structures in EFL countries, the EFL context may in some cases be considered far more complicated than individual ESL contexts. This complexity implies a need to revisit the basic 
theories of language teaching and learning from which CLT is derived. To talk of simple adaptation of the classroom techniques oversimplifies the task and is misleading for the future of CLT in an EFL context.

Another important impact of the complexity is the development of curriculum. Usually curriculum design starts from a needs analysis (Brindley, 1989; Brown, 1996). In an EFL context a needs analysis should be conducted to investigate the context of a particular program before beginning curriculum design to find out what are the enabling and limiting factors. This needs analysis is necessary in order to ask the right questions and to work with the limits and constraints of the context in deciding goals and objectives; developing teaching materials; and fulfilling teaching, testing, and evaluation goals. Dubin and Olshtain (1986) suggested such preliminary work, advocating a fact-finding stage. In this article, we refer to this as context assessment. In order to facilitate this context assessment, there should be a framework that can be helpful in recognizing the important factors and understanding the functions of these key factors in an EFL context. This article is a case study of such a context assessment stage and its integration into the design of curriculum.

\section{Research Context and Purpose}

This study originated from our concern about the introduction of CLT English teaching into Private Pui Ching Commercial College (PPCCC) in the city of Guangzhou, one of China's pioneering cities in economic and educational reform. PPCCC is a private institute founded in 1993, which now has 3,000 students in its seven departments. These are industry management, marketing, finance, accounting, law, foreign languages, and commercial information management. The college offers a three-year postsecondary diploma to its students, who are mainly from Guangdong province. Most of the students work in private or foreign companies after graduation. As a private college, it enjoys relative freedom in policy-making and sufficient funding. English as a foreign language is one of the two most important subjects in PPCCC (the other being computer science). The focus of its EFL program is to train students in all subjects to be competent in English for their future jobs. The general English requirements on graduation are:

1. Graduates are able to understand their work assignments in English in both written and oral form. Reading and understanding documents relevant to their work are also required.

2. Graduates are able to exchange ideas clearly with their colleagues in English. This includes social interaction, exchanging information, suggesting, persuading, negotiating, recommending, and warning, and so forth.

3. Graduates are able to write business letters, reports, and other documents relevant to their work. 
Consequently, the rationale for this study also derives from the PPCCC students' demand for developing better English communication skills for their future workplaces. The labor market expects its candidates to be fluent in English, especially in speaking and listening. Furthermore, according to an informal survey (Sun, Zhang, \& Yang, 1996) conducted at PPCCC, 90\% of the students who responded chose speaking and listening as "most important" among listening, speaking, reading, writing, and translation. Eighty-two percent of the students were not satisfied with their English classes at PPCCC and demanded a change. Similar requests have also been received at other universities and colleges in China, especially those in private or community colleges. English teachers, and the English program, at PPCCC are under tremendous pressure to modify the English teaching methodology, particularly as CLT methodology has gradually gained recognition in China. Students, especially in private colleges and universities, have a more urgent need for communicative competence than students in public universities because they rely on the labor market for a job after graduation. Correspondingly, private colleges and universities are more flexible in policy-making and administration than public universities. For example, because PPCCC is under the direction of its Board of Directors (mainly Hong Kong nationals and overseas Chinese), western theory and methodology are preferred.

Here we discuss the teaching of English in China in the context at PPCCC so that curriculum development issues in relation to CLT and the EFL context can be fully addressed. The first part of this article discusses the framework for context assessment of the language teaching program design at PPCCC, which offers a description of the context when CLT was introduced. The second part focuses on how the context was considered during curriculum development. Three key questions are discussed in order to clear the ground for this integration process. We have both taught English as a foreign language in China; one of us was an EFL teacher at PPCCC. The study's data collection is, therefore, based on direct involvement in the curriculum design in the context, including, but not limited to, daily observations of the teaching and learning situation and obtaining feedback from teachers and students.

\section{The EFL Context at PPCCC in China}

Brown (1994a) defined foreign language contexts as "those in which students do not have ready-made contexts for communication beyond their classroom" (p. 16). Dubin and Olshtain (1986) further explored the concept and put it into categories such as language setting, patterns of language use in society, group and individual attitudes toward language, and the political and national context. Brown's definition is too general for the purpose of this article. Dubin and Olshtain's categories display a clear and practical approach to finding facts in a context study to determine an appropriate teach- 
ing methodology. For our purposes, any given EFL context consists of specific and general factors in a certain English language program that directly influence how and the extent to which foreign language learners are exposed to, and acquire, a foreign language inside and outside the classroom. These factors interplay, and comprise both the condition and the provision of the language teaching program in a cultural, political, and educational situation in which English is neither an official language nor the native or working language of all or part of the citizens in the society. One of the key phrases of the above definition is "a given situation within a certain program." Due to the great diversity of different EFL contexts in different countries and even different institutes in one country (Xie \& Derwing, 1996), the definition of EFL context for this article is carefully confined to that of an individual program, that is, the English program at PPCCC. It is operational for the development of a program or the reconceptualization of an existing one. For example, in China there are (a) significant imbalances of economic and social development among regions, (b) unique local traditions and cultures, (c) various types of educational institutes (such as public, community, private colleges, and universities, etc.), and (d) differences in resources and in qualifications of teachers and so forth. All these make a strong case for analyzing the context on an individual basis rather than overgeneralizing about the situation.

According to the above definition, it is obvious that the EFL context is not only the language setting, but also the factors playing a role in CLT in EFL countries. Based on the framework provided by Dubin and Olshtain (1986), in the process of introducing CLT into PPCCC, the elements described below are used to form a framework to assess the context for a new language program (see Figure 1). The reason for choosing these elements is that they have a direct and evident impact on the success of a communicative language program and they are relatively easy to observe and analyze. This framework focuses only on the six most influential factors in three categories in the EFL context at PPCCC. However, this framework is not meant to be exclusive to PPCCC.

\section{Educational Policy}

Educational policy refers to the national, local, and institutional policies that fix the limits of a language program (McKay, 1992). In general, the policy for English teaching is encouraging in China (Wang, 1986). However, in different institutions in China the situation may be different. At PPCCC the following categories are explored as components of institutional policies: (a) funding; (b) criteria of student assessment ${ }^{1}$ and teacher evaluation; (c) employment policies (e.g., expatriate teachers); (d) size of the classes; and (e) teaching hours and schedule. 


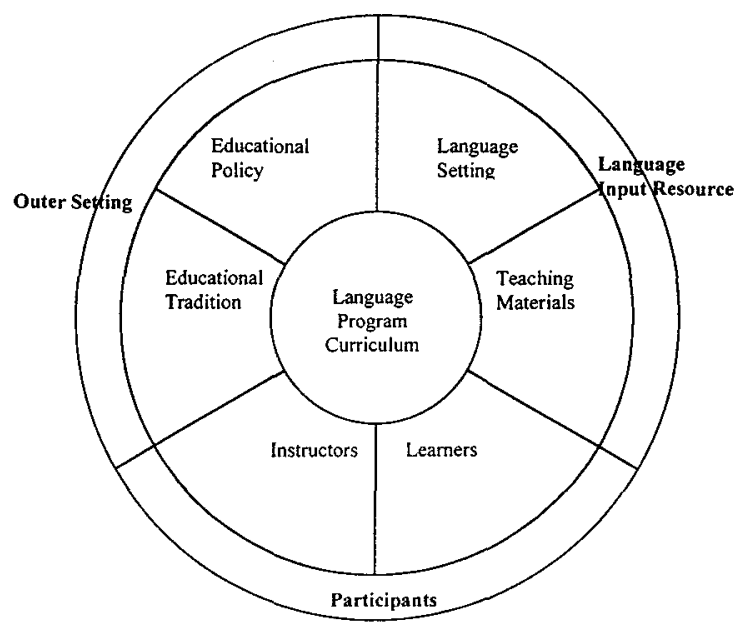

Figure 1. Elements of an EFL context.

As a private institution, PPCCC has much freedom in policy-making. The Board of Directors is enthusiastic about innovation in English teaching methodology. More resources and funding are allocated to English teaching than to any other subject. The national grammar-centered tests are challenged by new communicative-oriented assessment criteria, although students still take part in the College English Test. English classes are relatively small (20-30 students). Teaching hours are above the average in China (the average is about four to six hours per week, whereas it is more than 12 hours a week at PPCCC). The employment of teachers is relatively flexible. Teachers are encouraged to try new methods and technologies such as CLT and multimedia technology. Teachers are also expected to participate in inservice training programs, as well as adapt and design various teaching materials. These are important components in teacher evaluation.

\section{Educational Tradition}

Educational tradition refers to the positive and negative heritage of education history including traditional methodology and its effect on the preconceptions and behaviors of teachers and students, administration, parents, and other associated groups. The negative side of this heritage produces some substantial obstacles and unconscious preconceptions that impede CLT. This negative side causes extra pressure in teacher training; moreover, students often take longer to become accustomed to new classroom activities, which involve different views of knowledge and learning, of teacher roles, of learner roles, and of the student-teacher relationship ( $\mathrm{Li}, 1997)$. At PPCCC the teachers are from all over China; however, they tend to use the 
same teaching methods and share similar views on language teaching. English teaching at PPCCC used to be highly test-, teacher-, and textbookcentered. It emphasized delivery of knowledge rather than training for language competence. As a result, many teachers believe grammar and language points are the infrastructure of a language, and their students should be able to communicate effectively if they master this knowledge. For some teachers, teaching the right thing in the right way (in terms of grammar, etc.) is a moral responsibility rather than a simple issue of teaching methodology. Change is slow and painful. To expect an overnight methodology revolution is unrealistic and would exacerbate the difficulty of implementing innovation.

\section{Language Setting}

Language setting refers to how the target language is used in a country. It defines the availability of resources for authentic language input outside the classroom and how students use the foreign language after graduation. It could be interactive or passive. At PPCCC the study of language setting focuses on: (a) the extent of students' English input outside the classroom; (b) the language exposure; (c) the authenticity of the input; and (d) the appropriateness of the input.

In Guangzhou, fortunately, where the PPCCC is located, the language setting is promising. Two English newspapers and several English magazines are available. English radio broadcasts and TV channels from Hong Kong can also be accessed. Students are able to listen to the British Broadcasting Company (BBC) and Voice of America (VOA) to improve their listening, although the Chinese government does not publicly encourage it. At PPCCC more than 20 expatriate teachers communicate daily with the students. The English club is another effort to create appropriate language input for the students. However, compared with the language input of ESL students, access to English is still limited at PPCCC.

\section{Teaching Materials}

CLT features the use of authentic teaching materials. These comprise textbooks, as well as radio broadcasts, video programs, newspaper articles, and real-life dialogues. At PPCCC two kinds of difficulties regarding teaching materials are encountered: the availability of materials, and the adoption and adaptation of materials to teaching activities. The latter is more difficult than the former for PPCCC. Although resources are not sufficient, it is possible to obtain some materials from English-speaking countries through alumni and expatriate teachers. The problem lies in how to decide on level and appropriateness and the degree of language difficulty. The balance is hard to keep. It is also difficult to predict the students' problems when they encounter these materials in class. 
Brown (1996) suggested procedures for adopting and adapting materials. In an EFL context it is essential to modify the procedures first. At PPCCC expatriate teachers are encouraged to take a leading role in adopting and adapting materials into their teaching according to their experience and familiarity with the students. Another consideration is the political content of materials (Cooke, 1986). In China, English teachers are not supposed to use materials potentially harmful to the political structure or hazardous to the identity of Chinese culture. Morality is a big concern in China.

\section{Instructors}

CLT teachers are required to have native or close to native language competence and a good knowledge of the culture and society in English-speaking countries. At PPCCC the local teachers encounter two specific problems with CLT. The first is their lack of proficiency in English, especially in spoken English and sociolinguistic competence, although they all hold BAs in English. However, English is a foreign language, and English culture is foreign to them. They usually find it difficult to handle CLT activities in their own classrooms. The second problem is a tradition of language teaching in China that is characterized by teacher-centered teaching, structure-based instruction, and drill repetition. With such a tradition it is not surprising that these teachers have their own interpretation of CLT. Li (1997) reported that some teachers understand communicative teaching as merely a concentration on listening and speaking or language games. The same thing happens at PPCCC. For example, some teachers believe that communicative teaching simply means using more games to attract the students' attention. Some think CLT is a method for teaching spoken English, but not for reading and writing. Researchers have pointed out that it is more difficult to persuade teachers than the students in China to accept CLT (Anderson, 1993; also Burnaby \& Sun, 1989). It is important to ascertain what students' and teachers' preconceptions are and to offer integrated training so that their experiences can be used positively. As for expatriate teachers who are native English speakers, they may find they do not understand the host language, culture, or their students, which can also be a problem. As Harvey (1985) mentioned "EFL in China needs western experience and expertise, not western dogma" (p. 186).

\section{Learners}

EFL learners in a language program are from comparable cultural backgrounds. They usually share similar learning experiences and use similar learning strategies. This similarity is an indispensable factor for a curriculum developer to take into account. Despite this similarity, EFL students may have variations in their purposes for learning a foreign language (Stern, 1983). This implies that they may have different motivations for, and at- 
titudes toward, English learning when compared with ESL students. For CLT, student personality also plays an important role (Burstall, 1978; Brown, 1994b; Oxford, 1992). Are the students used to learning individually or cooperatively? Are they independent or dependent learners? How adaptable are they to new ways of learning? In general, the stereotype of Chinese students is that of dull learners who enjoy rote memorization of grammar rules and spend all their time sitting in the classroom emotionlessly refusing to participate in communicative activities. This is not necessarily true for all Chinese students.

At PPCCC if teaching activities are suitable to the student level and the principles are clearly demonstrated, students are happy to take part. In fact, we observed that in some of the expatriate teachers' classes, students surprised their teachers with their willingness and readiness to participate. They usually gave positive responses to the teaching and were satisfied with their improvement in English. Other researchers have reported similar findings in different institutions (Harvey, 1985; White, 1989).

At PPCCC, however, students' English language proficiency is generally low. When they enter the college they usually have a vocabulary of about $1,000-2,000$ words and phrases. They know basic grammar rules, but make mistakes when writing a paragraph. Their main learning strategy is still rote memorization and silent reading. Nevertheless, they are ready to change. These problems also have to be taken into account in developing an English language program.

\section{Integrating Context into Curriculum at PPCCC in China}

The framework of the EFL context at PPCCC is discussed above in relation to the six aspects of a language program. In the following section we discuss the process of integrating such a context into the curriculum at PPCCC by exploring three fundamental questions regarding (a) the teaching methodology, (b) teaching objectives, and (c) teaching activities. These questions, outlined below, are closely connected to the language-learning context and thus are of essential importance in designing an effective program. These questions are discussed in detail as the answers to them then define the primary characteristics of a program in a certain context and give guidelines for decision-making on various aspects of the curriculum design.

How communicative can a program be in the given EFL context in China, such as the one at PPCCC? CLT as a methodology requires sufficient language input and well-trained instructors. The conditions and provisions of a language environment, teaching materials, and instructors together define how the instructors will prepare and deliver their teaching and how the students will learn in the program.

What objectives can be realistically achieved for such a program in an EFL context? The objectives of a language program are to meet the learners' needs. 
EFL learners' needs are somewhat different from those of ESL learners (Sun, 1987). Considering the conditions of context, CLT program designers will need to focus on the objectives that are meaningful to the learners and realistic to the context.

What would the teaching activities look like in this context at PPCCC? Teaching activities should be supported by resources and the training of instructors. Moreover, such activities in an EFL context can be seen as forming an island in the sea of the native language (language setting, educational traditions, etc.) For EFL students, language input is limited mainly to English classes. In designing teaching activities it is necessary to have some remedial measures to help the students take in the limited language input. These specially designed activities should help those instructors not specifically trained in CLT to achieve the designed teaching objectives.

\section{How communicative can a program be in the given EFL context in China, such as the one at PPCCC?}

This question highlights the need for compromise between CLT and the traditional methodologies that still prevail in China. If there is not a dramatic change in the whole EFL education system, an exported or innovative program such as CLT can actually only dance on a traditional stage to a traditional audience. Compromise is unavoidable. The following facts indicate that innovation in language teaching at PPCCC involves compromise.

1. Traditional perceptions and views of language teaching still see language-learning as a process of delivering knowledge rather than of developing communicative skills.

2. Limited resources (such as language input and teaching materials) make it difficult to provide sufficient and authentic opportunities for the students to practice English.

3. Lack of qualified teachers for CLT and the traditional learning strategies of the students together make it difficult for CLT to be implemented.

Teacher training can be a key issue.

Learning processes occur both consciously and subconsciously (Littlewood, 1981). The development of language teaching methodology from structural to functional and notional presents a shift of focus. Structure is still an essential element of language. The belief that communicative methodology is more effective and efficient does not necessarily mean that methodologies centered on structure do not work at all. Johnson (1982) suggested a distinction between "communicative practice (with minimum control)" and "communicative drills" (p. 156), which accept the need for controlled practice. Yalden (1983) proposed a "proportional approach" in which "the first is simply to retain old techniques, but to adapt them to reflect the functional component of meaning more clearly." Then "the teacher tries 
to provide practice that will be more like communicative activities in the outside world" (p. 132).

All these efforts provide an opportunity to revive the old methodologies in a new view of language from a communicative orientation. Gatbonton and $\mathrm{Gu}$ (1994) reported their choice of a practical methodology as "one that combined the best of western-based communicative approaches (insistence on genuine communication as a medium for learning) and the best of traditional Chinese teaching methodology (reliance on activities that focus on the formal structure of language: text analysis, grammatical explanations, drills, text and rule memorization)" (p. 18). Li (1989) believes the communicative methodology and the Chinese traditional methodology can be complementary to each other. Similar attitudes can be found in Allen and Spada (1983), Maley (1984), White (1989), Fei and Duan (1993), and Rao (1996).

At PPCCC communicative language teaching is being conducted experimentally and in a unique way that involves compromise. The teaching of English is divided into two parts. A course of "Pui Ching English" is taught five to six hours per week, using the traditional teaching methodologies of grammar-translation and text explanation. Its focus is on reading and writing with emphasis on grammar and vocabulary, in accordance with the National English Syllabus in China. About 30 Chinese teachers deliver this course. These are experienced teachers who hold BAs in English. More than one third of them are teaching professors from well-known universities in China. The other course is "Pui Ching Oral English." This course is taught two hours per week and delivered by about 20 expatriate teachers. The Pui Ching Oral English concentrates on speaking and listening, with communicative competence as its core. Some of the expatriate teachers have a great deal of experience in communicative language teaching and some do not. Even those who lack experience in CLT include many more interactive classroom activities than the Chinese teachers. They tend to foster more authentic communication than their Chinese partners, possibly because they have had more exposure to CLT. These expatriate teachers are hired based on their qualifications and work experience. They all must hold a BA or master's degree, but not necessarily with an ESL/EFL major.

All 3,000 students at PPCCC are required to take both above courses for two years. The traditional teaching classes consist of about 50 students, and the communicative classes enroll 20. The college administration tries not to intervene in the expatriate teachers' teaching. Expatriate teachers have their own offices, and they are under the leadership of a relatively experienced teacher. The textbooks are used only for reference purposes, and teachers are encouraged to develop new teaching materials.

It is frequently observed that students appear to enjoy expatriate teachers' classes more than the traditional classes. In fact expatriate teachers privately complain to the local Chinese teachers that students are so enthusiastic in 
practicing English with them that they (expatriate teachers) have no private time. However, students tend to tell their Chinese teachers that they have a sense of security in traditional classes because they learn more grammar and vocabulary. It is worthwhile to point out that both groups of teachers teach to the best of their abilities. We do not equate expatriate teachers with CLT and local Chinese teachers with traditional methods, or argue that CLT is better than traditional methods. On the contrary, we argue for a balanced methodology depending on the conditions of the context.

It is interesting that the students appear to employ different learning strategies in traditional and communicative classes. They sit silently and memorize grammar points and vocabulary in the traditional classes, whereas they move around, talk, laugh, and even shout in communicative classes. These dual characteristics have brought confusion and frustration to both the Chinese and foreign teachers.

Obviously the arrangement of teaching discussed above is constrained overall by contextual condition. Traditional teaching and communicative teaching coexist because of the instructors' different backgrounds. The instructors play their own roles in teaching, and the students benefit from both. It is impractical to introduce CLT into PPCCC without considering the differences of instructors and other contextual elements, such as:

1. It is relatively easier for an expatriate teacher to use communicative methodology, at least in oral English.

2. Student adaptation to both CLT and traditional methodologies implies the feasibility of combining both methodologies in the curriculum.

3. Grammar and vocabulary teaching can be relatively more important than communication in EFL contexts like PPCCC because these bring both knowledge and security to the students when the language setting could not provide sufficient language input.

What objectives can be achieved realistically for such a program in this EFL context?

The main objective of a given language program is to satisfy the needs of the students. EFL students may have various purposes for learning English. These include: (a) to prepare for a future job; (b) to read technical materials only available in English; (c) to pass an examination in order to graduate; (d) to be qualified for the approval of a professional entitlement; (d) to study in English-speaking countries; (f) to emigrate to English-speaking countries; (g) to differentiate themselves from future contenders; $(h)$ to gain a job promotion; (i) to enjoy English literature; (j) to satisfy their curiosity about a foreign culture; and ( $\mathrm{k}$ ) to travel in other countries using English as an international language.

This list of purposes can be much longer, and every item may have some sub-items. Most Chinese students' motivations for learning a foreign lan- 
guage are concerned with the first three purposes, meaning that most students in China are learning English as a means to an end, a factor that an English program must take into consideration to maximize the use of students' time and to equip them with exactly what they need.

This distinction between integrative and instrumental objectives mentioned above has specific significance for CLT in China. First, helping students to learn English for a future job may be the only objective for most of the English programs in China. Second, this distinction helps to reinforce the teacher's preconceptions about CLT. Burnaby and Sun (1989) report that Chinese teachers believe CLT is applicable only to those who are going to live or study in English-speaking countries, and that the traditional method is most suitable for Chinese students. Burnaby and Sun propose that different methodologies be employed in teaching for different purposes in order to address the needs of the students. Looking at the situation at PPCCC, we believe that there should be no conflict between communication and using English instrumentally. Teaching English instrumentally and communicatively can happen simultaneously (Li, 1984; White, 1989; Sun, 1990; Forseth, 1991; Tool, 1992).

At PPCCC, in setting up the objectives of language teaching, the following facts are emphasized.

1. The students major in various business subject areas. The English requirement of their future professions plays a leading role in the objective-setting process.

2. The availability of authentic language input is limited. Expatriate teachers are great resources, and they offer more than they are expected to offer, but the ratio of students to teachers is as high as 100:1.

Complementary resources such as the English club, books in the library, and English movies are available, but still insufficient when compared with those of an ESL environment.

3. Most of the students will not live, study, or work in an English-speaking country.

4. The students expect to gain not only language competence, but also to be exposed to Western culture and the opportunity to broaden their thinking.

5. Based on a survey of former graduates of the College (Sun et al., 1996), most of the students will work in domestic or international enterprises in the future. They will use English mainly as an instrument and also for work-related communication purposes.

In translating these facts into objectives, it is clear that the goal of education is not to teach students everything they may need, but to prepare them with the skills necessary for a good beginning to their futures. Students equipped with the necessary skills can learn what they need more effectively 
and efficiently when they learn it in practice after they graduate from the College.

What would the teaching activities be like in the context at PPCCC?

Communicative teaching activities in ESL programs claim to have the following essential features.

1. They are task-based. According to Brown (1994a), task-based English teaching concentrates on communicative tasks that learners need to do in and outside the classroom.

2. They are learner-centered. The emphasis of teaching activity is placed on student initiative and interaction. Students are expected to participate in the activities and take responsibility for their learning (Nunan, 1988).

3. They emphasize the use of authentic language input. This means that authentic teaching materials, teachers' native or near-native language competence, and a true language setting are necessary for communication in the classroom (Munby, 1978).

In the adaptation of CLT to the EFL context, it is necessary to reexamine these characteristics with the following facts in mind.

1. Students may not have opportunities to undertake the pedagogical task outside the classroom immediately. Supplementary practice of a task is therefore necessary.

2. Grammar may be more important in EFL than in ESL. It may not be necessary to learn grammar systematically, but totally neglecting it may be even more harmful (Harvey, 1985; Murcia, 1991; Li, 1997). Brown (1994a) firmly points out that "for adults, the question is not so much whether to teach or not to teach grammar, but rather, what are the optimal conditions for overt teaching of grammar" (p. 349).

3. Language input is derived mainly from classroom activities in an EFL context. The language setting is insufficient for true CLT, and authentic materials are usually lacking.

4. Traditional methods of language teaching still have an impact on both teachers and students although the program is a communicative one.

5. In many ESL language programs, students attend classes three to four hours a day, five days a week, whereas an EFL language program may provide students four to 10 hours a week of exposure to English.

Various models of adapting communicative teaching activities in China have been provided (Allen \& Spada, 1983; Li, 1984; Maley, 1984; White, 1989; Forseth, 1991; Tool, 1992; Gatbonton \& Gu, 1994). Despite the various names and emphases of these models, they have prominent similarities. Each model contains some remedial activities to help bridge competence and information gaps and to help the students focus on the objectives of the teaching. Sometimes there is a preparatory component, which familiarizes the students with 
grammar, vocabulary and / or relevant background knowledge (White, 1989; Gatbonton \& Gu, 1994). Sometimes a consolidation activity is done after the central communicative activity to help students concentrate on the objective of the lesson (Gatbonton \& Gu). All three parts of an activity are taught communicatively, using interactive activities instead of drills or lectures. The formation of these models seems in accord with the weak version of CLT (Howatt, 1984) and the ideas of Littlewood (1981) who states, "one of the most characteristic features of communicative language teaching is that it pays systematic attention to functional as well as structural aspects of language" (p. 1, see also Littlewood, 1984).

In designing teaching activities, two processes are involved. One is the process of selecting language skills to form teaching content to fulfill the achievement of the objective. The second is to convert this content into teaching activities that provide communicative tasks for students to carry out. In an EFL situation, it is necessary to suggest a complementary process: that of discovering the grammar, vocabulary, and background knowledge that are relevant to the task and helpful for students in undertaking the task.

Figure 2 shows the process of designing a communicative teaching activity in an ESL context. An objective is broken down into different language skills, which are then used to design a pedagogical task. Figure 3, on the other hand, shows the relationship between a pedagogical task and controlled pedagogical task in an EFL context. A pedagogical task is the communicative teaching activity aimed at building a student's language competence (Savignon, 1972). A controlled pedagogical task is the activity designed first to help students to learn the grammar, vocabulary, and background knowledge necessary for carrying out the pedagogical task. In teaching, controlled pedagogical tasks are used to prepare the students for the pedagogical task. Both tasks should keep the communicative nature of the task in mind, but with a different focus and a different method of implementation. A pedagogical task is learner-centered, with full interaction and minimum control, whereas in a controlled task the teacher plays the role of director, and the teaching activity is designed so that grammar, vocabulary, and background knowledge are practiced or introduced.

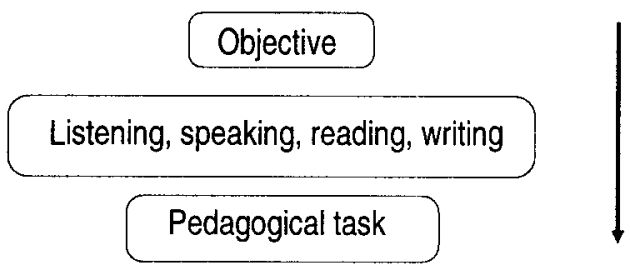

Figure 2. From the objective to the pedagogical task. 


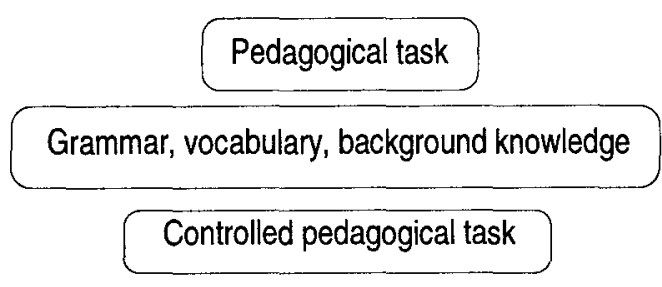

(The process of designing teaching activities)

Figure 3. From the pedagogical task to the controlled pedagogical task.

At PPCCC there is a traditional component and a communicative component in the EFL program. The former is carried out by Chinese teachers using text analysis, grammar, and drilling, whereas the latter is taught by expatriate teachers using communicative methodology. The advantages of this arrangement are: (a) both local and expatriate teachers can do what they are good at; (b) in communicative classes students have the opportunity to practice the grammar and vocabulary they learn in traditional classes; and (c) both local teachers and students enjoy the security of keeping the familiar. The disadvantages of such an arrangement are also evident; (a) students are not well motivated in the traditional classes, and the learning is not efficient; (b) consistency of teaching between the two kinds of classes is difficult to obtain as different textbooks and methodologies are used; (c) students are sometimes confused by the different philosophies underlying the different methodologies; (d) conflicts arise in the allocation of resources, meaning that eclecticism is used more often than optimization in order to reach a compromise; (e) teachers do not see the necessity of learning from each other because the focus and methodology are so different that they do not know how to integrate CLT with traditional teaching methods or vice versa.

Currently local teachers in PPCCC are trying to adapt the communicative methodology to traditional classes. The plan is designed on a transitional basis. The first stage is to introduce some communicative methods into traditional teaching, for example, using interactive activities in teaching grammar or transferring text analysis into classroom discussion so the students can have more opportunity to speak English. Second, local teachers will try to convert lessons used in the traditional classes into communicative activities. The goal is to reorganize the teaching procedure and produce a shift of focus, but not to change the content of the textbooks. For example, if the topic of a lesson is environmental protection, a classroom activity will be designed to ask the students to do some research on this topic and discuss it in small groups. The textbook is used only as the background for this activity. The teacher is no longer the center of the classroom. His or her duty is to help students complete the task and monitor the process of the activity. 
Grammar and vocabulary are taught only when necessary. Therefore, the emphasis is on teacher training at this stage. Finally, a new syllabus based on the needs of our students is being developed, the focus of which will be communicative language competence. As no compulsory national syllabus is available for three-year professional colleges like PPCCC in China, the College can develop its own. Teaching activities in this syllabus will be taskbased and learner-centered. Grammar and vocabulary will be integrated into teaching activities when a central communicative task requires them.

The first and second stages of this adaptation are underway. Volunteer teachers are being assisted by the Department of English and experienced expatriate teachers to participate in the curriculum change. Some of the experimental classes are quite successful; however, some remain a little chaotic. Finally, two significant phenomena are worth noting. One is the impact of traditional language teaching preconceptions. Some teachers still concentrate on grammar and discrete language points, although the teaching activities have changed. For these teachers a new activity means simply changing exercises based on the text. This indicates that the adoption of a communicative view of language is more important than introducing new teaching techniques. If teachers see language as a composition of structures and vocabulary, they will surely misinterpret the communicative teaching activity.

The other important phenomenon is that students tend to use their native language-Chinese-when a classroom task arouses their interest. Two factors could contribute to this shift of language. First, teachers and students have a common language. Second, as adults, students' knowledge and experience are far more developed than their abilities to express themselves in English. This tension between what they want to say and what they can say in a foreign language is one of the basic conflicts in introducing CLT to China. CLT benefits from true communication; however, students may not be able to manage it due to their relatively low proficiency in the language.

\section{Implications From This Case}

This articles discusses the integration of the EFL context into the curriculum in China using the CLT program at PPCCC as an exemplar. A preliminary stage of context assessment of curriculum design in an EFL context is suggested. A framework for examining context is provided for this purpose. In trying to integrate context into curriculum, three fundamental questions regarding the teaching methodology, teaching objectives, and teaching activities are raised and discussed in relation to PPCCC. The practice in PPCCC suggests that the adaptation of CLT to various EFL contexts is first and foremost about curriculum development, that is, integrating the context into a communicative language teaching curriculum. Another suggestion high- 
lights that a compromise between CLT methodology and the conditions and provisions of the context should be considered and implemented.

The problems of adapting communicative language teaching methodology in this EFL context may be partly addressed by studying the context first in designing the curriculum. In doing so, the following implications may be helpful before designing a communicative curriculum in an EFL context in China.

1. In EFL teaching, the impact of the context on a program is more significant than in an ESL context. The more we know about the context, the better we can adapt this new methodology to the program.

2. Introducing new methods for classroom activities is helpful, but not sufficient. The adaptation should start from the beginning of the curriculum design and address the teaching and learning beliefs of the teachers and the needs of the students. The conditions of the context should be taken into account throughout the whole process of the curriculum development.

3. Adaptation of teaching methodology will be more successful if the theory of learning and teaching from which CLT methodology is derived is reviewed and shared among the teachers and students with the characteristics of the program context in mind.

Finally, we believe that the essential questions addressed throughout this article should be revisited and reconsidered in every EFL context during the process of curriculum development. It is, however, not enough for the curriculum planners or developers to do this sort of questioning. Rather, all teachers in the context must also ask these questions and try to integrate traditional methodologies with the communicative approaches. Only then will the needs of the students be served in such a curriculum.

\begin{abstract}
Note
${ }^{1}$ In China the National Matriculate Examination and the College English Tests are designed to emphasize reading and grammar. If an English language program neglects this assessment requirement, it will meet resistance from students. However, these examinations are not compulsory for all college students in China. Universities and colleges can set their own standards and assess at their own discretion, especially those three-year colleges. PPCCC has its own assessment system for the specific needs of its students.
\end{abstract}

\title{
Acknowledgments
}

The authors would like to thank Sandie Kouritzin and Patrick Mathews, as well as TESL Canada Journal's anonymous reviewers, for their feedback in the revision stage.

\section{The Authors}

Guangyong Sun is the Assistant President of Private Pui Ching Commercial College. He has taught EFL in China for more than 10 years. He was a visiting scholar at the University of Alberta in 1999 studying communicative language teaching, a focus of his recent research. He can be reached at guangyong_sun@21cn.com. 
Liying Cheng is an assistant professor in Teaching English as a Second Language in the Faculty of Education, Queen's University. She has taught ESL/EFL in many parts of the world including China and Canada. Her research interests are in second and foreign teacher education and testing and assessment. She can be reached at chengl@educ.queensu.ca.

\section{References}

Allen, W., \& Spada, N. (1983). Designing a communicative syllabus in the People's Republic of China. In R.R. Jordan (Ed.), Case studies in ELT (pp. 132-145). London: Collins ELT.

Anderson, J. (1993). Is a communicative approach practical for teaching English in China? Pros and cons. System, 21(4), 471-480.

Bachman, L.F. (1990). Fundamental considerations in language testing. Oxford, UK: Oxford University Press.

Barlow, T.E., \& Lowe, D. (1985). Chinese reflections: Americans teaching in the People's Republic. New York: Praeger.

Breen, M., \& Candlin, C. (1980). The essentials of a communicative curriculum in language teaching. Applied Linguistics 1(2), 90-112.

Brindley, G. (1989). The role of needs analysis in adult ESL program design. In R.K. Johnson (Ed.), The second language curriculum (pp. 63-78). Cambridge, UK: Cambridge University Press.

Brown, H.D. (1994a). Teaching by principles: An interactive approach to language pedagogy. Englewood Cliffs, NJ: Prentice-Hall.

Brown, H.D. (1994b). Principles of language learning and teaching. Englewood Cliffs, NJ: Prentice-Hall.

Brown, J.D. (1996). The elements of language curriculum: A systematic approach to program development. Boston, MA: Heinle \& Heinle.

Brumfit, C. (1984). Communicative methodology in language teaching. Cambridge, UK: Cambridge University Press.

Burnaby, B., \& Sun, Y. (1989). Chinese teachers' views of western language teaching: Context informs paradigms. TESOL Quarterly, 23, 219-238.

Burstall, C. (1978). Factors affecting foreign-language learning: A consideration of some recent research findings. Language teaching and linguistics survey. Cambridge, UK: Cambridge University Press.

Cooke, D. (1986). EFL and development. [Special Issue]. TESL Canada Journal, 3(1),127-34.

Dubin, F., \& Olshtain, E. (1986). Course design: Developing programs and materials for language learning. Cambridge, UK: Cambridge University Press.

Fei, X.P., \& Duan, L.L. (1993). Foreign language teaching: The traditional methods and the communicative approach. Modern Foreign Languages, 59(1), 37.

Forseth, R. (1991). Conversation class: How to keep your students talking (in English). ELIC Teaching, 8, 35-44.

Gatbonton, E., \& Gu, G. (1994). Preparing and implementing a task-based ESL curriculum in an EFL setting: Implications for theory and practice. TESL Canada Journal, 11(2), 9-29.

Habermas, J. (1970). Towards a theory of communicative competence. Inquiry, 13, 360-375.

Harvey, P. (1985). A lesson to be learned: Chinese approaches to language learning. ELT Journal, 39(3), 183-186.

Howatt, A.P.R. (1984). A history of English language teaching. Oxford, UK: Oxford University Press.

Hymes, D. (1971). Competence and performance in linguistic theory. In R. Huxley \& E. Ingram (Eds.), Language acquisition: Models and methods. London: Academic Press

Jakobovits, L. (1970). Foreign language learning: A psycholinguistic analysis of the issue. Rowley, MA: Newbury House.

Johnson, K. (1982). Communicative syllabus design and methodology. Oxford, UK: Pergamon.

Jones, L. (1992). Communicative grammar practice. Cambridge, UK: Cambridge University Press. 
Li, D.F. (1997). Absolutely not the same: The potential and problems of communicative language teaching in China. Unpublished doctoral dissertation, University of Alberta.

Li, G. (1989). On the possibility of combining the traditional methods with the communicative approach: How to teach English major students in the first two years in tertiary institutions. Foreign Languages, 32(1), 1-9.

Li, X.J. (1984). In defense of the communicative approach. ELT Journal, 38(1), 2-13.

Littlewood, W. (1981). Communicative language teaching. Cambridge, UK: Cambridge University Press.

Littlewood, W. (1984). Foreign and second language learning: Language acquisition research and its implications for the classroom. Cambridge, UK: Cambridge University Press.

Maley, A. (1984). On chalk and cheese, babies and bathwater and squared circles: Can traditional and communicative approaches be reconciled? In P. Larson, E. Judd, \& D. Messerschmitt (Eds.), On TESOL '84: A brave new world for TESOL: Selected papers from the 18th annual convention of TESOL (pp. 6-11). Houston, TX: TESOL.

McKay, S.L. (1992). Teaching English overseas: An introduction. Oxford, UK: Oxford University Press.

Munby, J. (1978). Communicative syllabus design. Cambridge, UK: Cambridge University Press.

Murcia, M. (1991). Grammar pedagogy in second and foreign language teaching. TESOL Quarterly, 25, 459-480.

Nunan, D. (1988). The learner-centered curriculum. Cambridge, UK: Cambridge University Press.

Oxford, R.L. (1992). Who are our students? A synthesis of foreign and second language research on individual differences with implications for international practice. TESL Canada Journal, 9(2), 30-49.

Penner, J. (1995). Change and conflict: Introduction of the communicative approach in China. TESL Canada Journal, 12(2), 1-17.

Rao, Z.H. (1996). Reconciling communicative approaches to the teaching of English with traditional Chinese methods. Research in the Teaching of English, 30, 458-71.

Richards, J.C., \& Rodgers, T. (1986). Approaches and methods in language teaching: A description and analysis. Cambridge, UK: Cambridge University Press.

Sampson, G.P. (1984). Exporting language teaching methods from Canada to China. TESL Canada Journal, 1(1), 19-32.

Savignon, S.J. (1972). Communicative competence: An experiment in foreign language teaching. Philadelphia, PA: Center for Curriculum Development.

Savignon, S.J. (1997). Communicative competence: Theory and classroom practice. New York: McGraw Hill.

Stern, H.H. (1983). Fundamental concepts of language teaching. Oxford, UK: Oxford University Press.

Sun, G.Y., Zhang, Y.G., \& Yang, T.N. (1996). Report on the survey of English classes. Unpublished report at PPCCC. Guangdong, China: Private Pui Ching Commercial College.

Sun, Y. (1987). An EFL needs assessment: Chinese students at a Canada university. TESL Canada Journal, 5(1), 27-44.

Sun, Z. (1990). Using "case studies" in oral English classes. English Teaching Forum, 28(4), 27-28.

Tool, D. (1992). Teaching large conversational classes without media aids. English Teaching Forum, 30(2), 32-33.

Wang, K. (1986). Teaching English as a foreign language in China. TESL Canada Journal, 3(1), 153-60.

White, C.J. (1989). Negotiating communicative language learning in a traditional setting. ELT Journal, 43(3), 213-20.

Xie, M., \& Derwing, T.M. (1996). Adults in community schools in Beijing, China. Journal of Multilingual and Multicultural Development, 17, 385-395.

Yalden, J. (1983). The communicative syllabus: Evolution, design and implementation. Oxford, UK: Pergamon. 